\title{
Oxytocin and Oxytocinase in the Obese and Nonobese Parturients during Induction and Augmentation of Labor
}

\author{
Annemaria De Tina, MD, FRCPC ${ }^{1,2}$ Jeremy Juang, MD, PhD ${ }^{1,3}$ Thomas F. McElrath, MD, $\mathrm{PhD}^{4}$
} Jack D. Baty, $\mathrm{BA}^{5}$ Arvind Palanisamy, MD, FRCA ${ }^{6 \odot}$

\footnotetext{
${ }^{1}$ Department of Anesthesiology, Perioperative and Pain Medicine, Brigham and Women's Hospital, Harvard Medical School, Boston, Massachusetts

2 Department of Anesthesiology, McMaster University, Hamilton, Ontario, Canada

${ }^{3}$ Department of Anesthesiology, Massachusetts Eye and Ear Infirmary, Boston, Massachusetts

${ }^{4}$ Division of Maternal-Fetal Medicine, Department of Obstetrics and Gynecology, Brigham and Women's Hospital, Harvard Medical School, Boston, Massachusetts

${ }^{5}$ Division of Biostatistics, Washington University School of Medicine, St. Louis, Missouri

${ }^{6}$ Department of Anesthesiology, Washington University School of Medicine, St. Louis, Missouri
}

\author{
Address for correspondence Arvind Palanisamy, MD, FRCA, \\ Department of Anesthesiology, Washington University School of \\ Medicine, 660 S Euclid Avenue, St. Louis, MO 63110 \\ (e-mail: arvind.palanisamy@wustl.edu).
}

Am J Perinatol Rep 2019;9:e177-e184.

\begin{abstract}
Keywords

- obesity

- pregnancy

- oxytocin

- induction of labor

- augmentation of labor

- oxytocinase

Objective To investigate differences in oxytocin (OXT) biodistribution between nonobese and obese parturients during labor.

Study Design Patients with body mass index (BMI) of either $\geq 18 \leq 24.9 \mathrm{~kg} / \mathrm{m}^{2}$ ("nonobese") or $\geq 30 \mathrm{~kg} / \mathrm{m}^{2}$ ("obese") undergoing elective induction of labor were included ( $N=25$ each). Blood samples were collected at baseline $\left(T_{0}\right)$, and 20 minutes after maximal OXT augmentation or adequate uterine contractions $\left(T_{1}\right)$ for OXT and oxytocinase assays. A mixed-model repeated-measures analysis of variance was used to test for group versus time interaction and analysis of covariance to detect a difference in OXT level at $T_{1}$. Data presented as mean \pm standard deviation or median (interquartile range), with $p<0.05$ considered significant.

Results The mean BMls $\left(\mathrm{kg} / \mathrm{m}^{2}\right)$ were $22.1 \pm 1.6$ and $35.9 \pm 5.1$ in the nonobese and obese groups, respectively. No differences were observed in either the duration of OXT infusion, total dose of OXT, or plasma OXT $(\mathrm{pg} / \mathrm{mL})$ either at $\mathrm{T}_{0}$ or $\mathrm{T}_{1}$. However, plasma oxytocinase $(\mathrm{ng} / \mathrm{mL})$ was significantly lower at $\mathrm{T}_{0}(1.41[0.67,3.51]$ vs. $0.40[0.29$, 1.12 ]; $p=0.03$ ) in the obese group.

Conclusion We provide preliminary evidence that the disposition of OXT may not be different between obese and nonobese women during labor.
\end{abstract}

(1) Arvind Palanisamy's ORCID is https://orcid.org/0000-0001-84601759.

received

January 27, 2019

accepted after revision

April 12, 2019
DOI https://doi.org/

10.1055/s-0039-1692196. ISSN 2157-6998.
Copyright $\odot 2019$ by Thieme Medical Publishers, Inc., 333 Seventh Avenue, New York, NY 10001, USA. Tel: +1(212) 584-4662.
License terms

(c) (1) $\ominus$ (5) 
In the United States, more than one-third of pregnant women are obese (prepregnancy body mass index [BMI] $\geq 30 \mathrm{~kg} /$ $\left.\mathrm{m}^{2}\right)^{1,2}$ and have an approximate $35 \%$ risk of cesarean delivery (CD) especially during the first stage of labor. ${ }^{3-5}$ Though increased risk for $\mathrm{CD}$ in this population is likely multifactorial, ${ }^{6,7}$ labor dystocia appears to play a predominant role. The diagnosis of labor dystocia, however, is predicated on the assumption that labor curves are similar for both groups, and that the pharmacokinetics of oxytocin (OXT) used for labor augmentation is comparable between obese and nonobese parturients. It is now known that labor curves are different in obese and nonobese parturients ${ }^{8,9}$; however, no study has directly examined differences in pharmacokinetics of OXT between these two groups. Especially, differences in BMI account for one-fifth of variability in OXT requirements during labor. ${ }^{10}$ This is a critical knowledge gap considering that there are significant differences in pharmacokinetic parameters between obese and nonobese patients in the nonobstetric setting, ${ }^{11,12}$ along with preclinical data suggesting that obesity is associated with lower OXT and higher oxytocinase activity. ${ }^{13}$ Therefore, in this preliminary study, we hypothesized that obese women will have lower plasma OXT and a higher plasma oxytocinase level at baseline compared with nonobese women. Furthermore, because of the increased volume of distribution in obesity, ${ }^{11}$ we speculated that the magnitude of rise in plasma OXT will be lower in obese compared with nonobese women during labor augmentation with OXT. To investigate this hypothesis, we designed a prospective, observational cohort study to compare the plasma levels of OXT and oxytocinase in obese and nonobese women at both induction and during augmentation of labor.

\section{Methods}

This prospective, observational cohort study was conducted after appropriate Institutional Research Board approval (\# 2015P002040) at the labor and delivery unit of the Brigham and Women's Hospital, a tertiary-care center with an annual clinical volume of $\sim 7,000$ births. All methods reported here were performed in accordance with institutional guidelines and regulations, and complies with all recommendations suggested by the STROBE statement. ${ }^{14}$ Patients at term gestation ( $\geq 37$ weeks) were eligible for enrollment if they were older than the age of 18 years, undergoing induction of labor with OXT, and had a prepregnancy BMI of either $\geq 18 \leq 24.9 \mathrm{~kg} / \mathrm{m}^{2}$ ("nonobese") or $\geq 30 \mathrm{~kg} / \mathrm{m}^{2}$ ("obese"). Patients were excluded if they presented in labor, were overweight (prepregnancy BMI of $25-29.9 \mathrm{~kg} / \mathrm{m}^{2}$ ), or had a relative contraindication to venipuncture (suspected or known coagulopathy, or hematologic disorder). Patient recruitment occurred between November 2015 and April 2017. Eligible patients were approached by a research investigator at the time of admission to labor and delivery unit and provided with an information sheet that explained the purpose of the study. Patients who expressed interest were recruited after a thorough history and clinical examination and a formal written informed consent. Each enrolled participant was assigned a sequential subject identification number, and all pertinent demographic information were collected.

A baseline basal blood sample $(10 \mathrm{~mL})$ was collected from each participant at the time of placement of an intravenous (IV) catheter prior to initiation of OXT infusion $\left(\mathrm{T}_{0}\right)$. A second blood sample $(10 \mathrm{~mL})$ was collected from the opposite arm when no further increase in OXT was likely (either 3-5 uterine contractions in a 10-minute period or at a maximal OXT augmentation rate of $20 \mathrm{mIU} / \mathrm{min})\left(\mathrm{T}_{1}\right)$. This sample was drawn from the arm opposite to the arm with the IV catheter. Blood samples were collected into BD Vacutainer containing $10.8 \mathrm{mg}$ of $\mathrm{K}_{2}$ EDTA, immediately placed on ice, centrifuged at $1,600 \times \mathrm{g}$ for 15 minutes at $4^{\circ} \mathrm{C}$, and the resultant plasma stored at $-80^{\circ} \mathrm{C}$ before assays. For the OXT assay, plasma was thawed, C-18 extracted, and assayed in duplicate using a commercially available OXT ELISA kit (EIA kit \# EK-051-01, Phoenix Pharmaceuticals, Inc.). Oxytocinase was assayed in unextracted plasma using the human LNPEP (leucyl-cystinyl aminopeptidase) sandwich ELISA kit (\# LS-F11924, Lifespan Biosciences, Inc.) according to manufacturer's instructions. Data on OXT use, total cumulative OXT dose until $\mathrm{T}_{1}$, and duration of OXT administration (from $\mathrm{T}_{0}$ to $\mathrm{T}_{1}$ ) were collected. The study was terminated after collection of the $T_{1}$ sample.

\section{Statistical Analysis}

Our primary outcome was to determine if there was a baseline difference in plasma OXT between the obese and nonobese groups at induction of labor. Our secondary outcomes were differences in oxytocinase levels and the magnitude of change in plasma OXT from $\mathrm{T}_{0}$ to $\mathrm{T}_{1}$ in both groups during labor augmentation. Given a mean baseline OXT level of $45 \mathrm{pg} / \mathrm{mL}$ and standard deviation of $20 \mathrm{pg} / \mathrm{mL}$ in nonobese parturients, ${ }^{15}$ we estimated that 19 patients would be required per group to show a $40 \%$ decrease in plasma OXT in the obese group for an $\alpha$ of 0.05 and $80 \%$ power. Because of the unpredictability of labor and challenges in the expeditious processing of samples after hours, we decided to enroll 25 patients per group to account for the possible attrition. Numeric variables were compared with either independent sample $t$-tests or Wilcoxon's rank-sum test for data with significant outliers. Categorical variables were compared with Pearson's chi-square or Fisher's exact tests as appropriate. To test for interaction between BMI category and the magnitude of change from $\mathrm{T}_{0}$ to $\mathrm{T}_{1}$, a mixed-model repeatedmeasures ANOVA was used. If group versus time interaction was not significant, the analysis was re-run without the interaction term. In addition, an analysis of covariance was performed to determine if there was a difference in OXT level at $\mathrm{T}_{1}$ after adjusting for the difference in oxytocinase level at $\mathrm{T}_{0}$ and cumulative OXT dose. Correlations between cumulative OXT dose and OXT and oxytocinase were determined using Spearman's correlation. Data are presented either as median (interquartile range), mean \pm standard deviation, or $\%$ as appropriate. All tests were two tailed and a $p$-value of $<0.05$ was accorded statistical significance. The data analysis for this article was generated using SAS software, version 9.3 of the SAS System for Windows. Copyright 2010 SAS Institute Inc (Cary, NC). 


\section{Results}

A total of 56 eligible patients were approached for the study. Five declined participation (two nonobese and three obese patients), and one nonobese patient was rescheduled for induction at a later date. Overall, we recruited 25 nonobese and obese subjects each for the study. $\mathrm{T}_{0}$ samples were obtained in 23/25 patients in both groups. $\mathrm{T}_{1}$ samples were obtained in 19/25 subjects in the nonobese and 13/ 25 in the obese groups. Paired samples (both $T_{0}$ and $T_{1}$ samples from the same patient) were available for 18/25 nonobese and 12/25 obese subjects. All samples were assayed for plasma OXT. Because of inadequate sample volume, oxytocinase assay was not performed in one patient in the nonobese and two patients in the obese groups at $\mathrm{T}_{0}$, and two patients in the nonobese and one patient in the obese groups at $\mathrm{T}_{1}$. The flowchart detailing patient recruitment is presented in -Fig. 1.
Both groups were well matched at baseline except for a higher proportion of cervical ripening in obese (48\%) compared with nonobese ( $8 \%$ ) patients $(p=0.002$, - Table 1$)$. Details of OXT and oxytocinase levels at $T_{0}$ and $T_{1}$, total cumulative dose of OXT administered until $\mathrm{T}_{1}$, and duration of OXT administration are presented in - Table 2 . There were no differences either in the plasma OXT level at $\mathrm{T}_{0}$ (351 [56, $790]$ vs. $135[14,534] \mathrm{pg} / \mathrm{mL} ; p=0.39)$ and $\mathrm{T}_{1}(463[15,791]$ vs. $320[14,768] \mathrm{pg} / \mathrm{mL} ; p=0.95$ ) (-Fig. 2). However, plasma oxytocinase was significantly lower at $\mathrm{T}_{0}$ in the obese group $(1.41[0.67,3.51]$ vs. $0.40[0.29,1.12] \mathrm{ng} / \mathrm{mL} ; p=0.03)$ but not at $\mathrm{T}_{1}(1.35[0.67,3.53]$ vs. $0.32[0.18,4.03] \mathrm{ng} / \mathrm{mL}$, nonobese versus obese, respectively; $p=0.44$ ) (-Fig. 3). Similarly, there was no difference in the total cumulative dose of OXT received during the study $(3,396 \pm 1,602$ vs. $3,793 \pm 2,819 \mathrm{mIU}$; $p=0.65$ ) nor was there a difference in the total duration of OXT administration (397 \pm 159 vs. $537 \pm 629$ minutes; $p=0.45$ ) between the nonobese and obese groups.

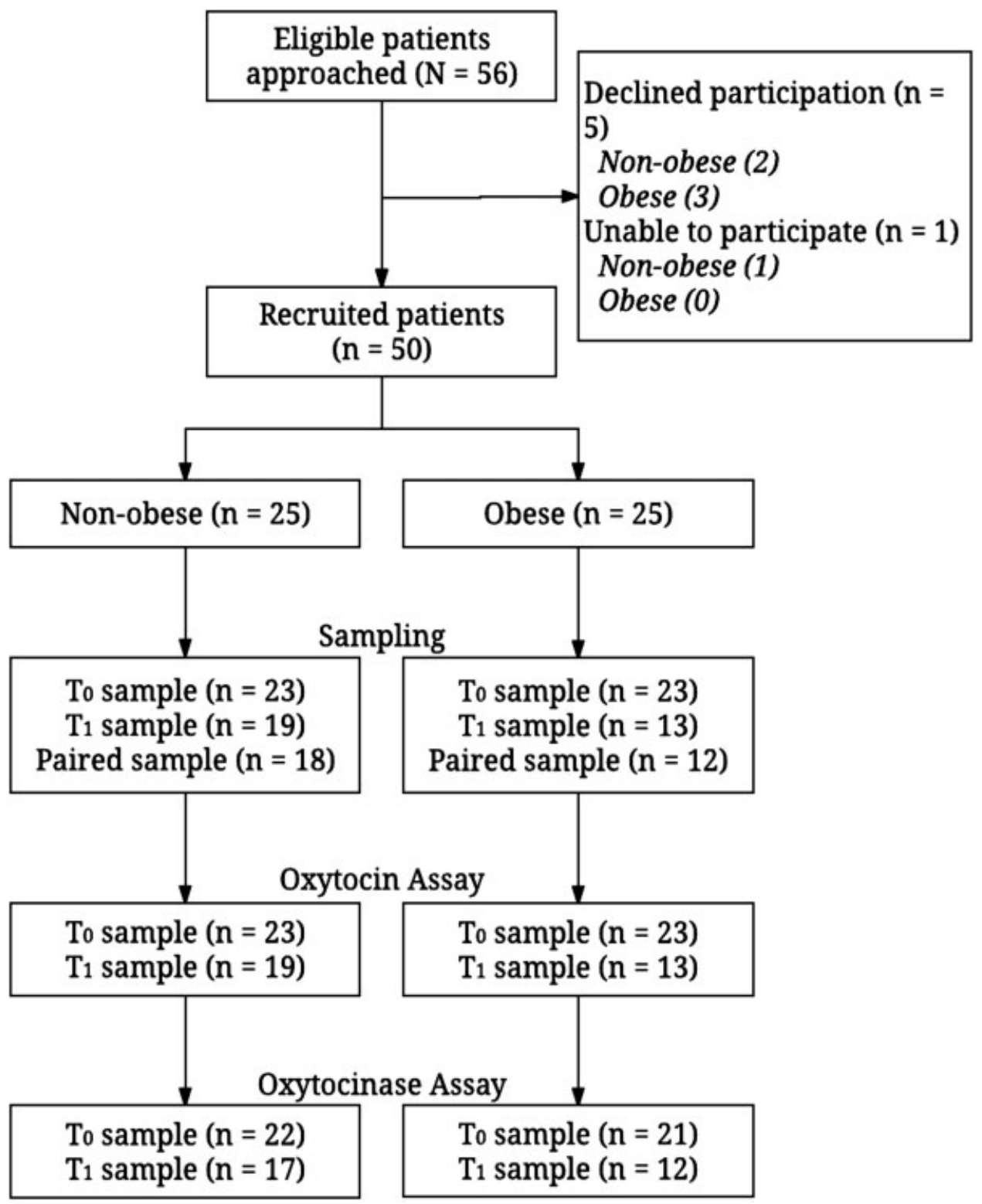

Fig. 1 A detailed flowchart indicating patient recruitment and sample collection during the course of the study. 
Table 1 Demographic and labor induction data in nonobese and obese parturients

\begin{tabular}{|l|l|l|l|l|l|}
\hline \multirow{2}{*}{} & Nonobese & \multicolumn{2}{l|}{ Obese } & \multirow{2}{*}{$p$-Value } \\
\cline { 2 - 6 } & $n$ & Mean \pm SD or $\%$ & $n$ & Mean \pm SD or \% \\
\hline Age $(\mathrm{y})$ & 25 & $31.32 \pm 4.47$ & 25 & $33.04 \pm 5.31$ & 0.40 \\
\hline BMI $\left(\mathrm{kg} / \mathrm{m}^{2}\right)$ & 25 & $22.13 \pm 1.59$ & 25 & $35.89 \pm 5.09$ & $<0.0001$ \\
\hline Gestational age $(\mathrm{wk})$ & 25 & $39.24 \pm 1.05$ & 25 & $39.00 \pm 1.26$ & 0.48 \\
\hline Gestational weight gain $(\mathrm{kg})$ & 25 & $15.2 \pm 5.5$ & 19 & $12.8 \pm 4.4$ & 0.13 \\
\hline Multiparity & 12 & 48 & 17 & 68 & 0.44 \\
\hline Cervical ripening & 2 & 8 & 12 & 48 & 0.002 \\
\hline Maximal oxytocin augmentation & 4 & 16 & 7 & 28 & 0.50 \\
\hline Artificial rupture of membranes & 21 & 84 & 20 & 80 & 0.71 \\
\hline Vaginal delivery & 24 & 96 & 21 & 84 & 0.35 \\
\hline Cesarean delivery & 1 & 4 & 4 & 16 & \\
\hline
\end{tabular}

Abbreviations: BMI, body mass index; SD, standard deviation.

Table 2 Oxytocin and oxytocinase data in nonobese and obese parturients

\begin{tabular}{|c|c|c|c|c|c|}
\hline & \multicolumn{2}{|c|}{ Nonobese } & \multicolumn{2}{|c|}{ Obese } & \multirow[t]{2}{*}{$p$-Value } \\
\hline & $n$ & $\begin{array}{l}\text { Median (IQR) or } \\
\text { Mean } \pm \text { SD }\end{array}$ & $n$ & $\begin{array}{l}\text { Median (IQR) or } \\
\text { Mean } \pm \text { SD }\end{array}$ & \\
\hline Oxytocin $\mathrm{T}_{0}(\mathrm{pg} / \mathrm{mL})$ & 23 & $351(56,790)$ & 23 & $135(14,534)$ & 0.39 \\
\hline Oxytocin $\mathrm{T}_{1}(\mathrm{pg} / \mathrm{mL})$ & 19 & $463(15,791)$ & 13 & $320(14,768)$ & 0.95 \\
\hline Oxytocinase $\mathrm{T}_{0}(\mathrm{ng} / \mathrm{mL})$ & 22 & $1.41(0.67,3.51)$ & 21 & $0.40(0.29,1.12)$ & 0.03 \\
\hline Oxytocinase $\mathrm{T}_{1}(\mathrm{ng} / \mathrm{mL})$ & 17 & $1.35(0.67,3.53)$ & 12 & $0.32(0.18,4.03)$ & 0.44 \\
\hline Cumulative oxytocin dose (mIU) & 19 & $3,396 \pm 1,602$ & 13 & $3,793 \pm 2,820$ & 0.65 \\
\hline Duration of oxytocin administration (min) & 19 & $397.5 \pm 159.2$ & 13 & $537.3 \pm 629.3$ & 0.45 \\
\hline $\mathrm{T}_{1}-\mathrm{T}_{0}$ oxytocin $(\mathrm{pg} / \mathrm{mL})$ & 18 & $-6.50(-96.00,4.00)$ & 12 & $-1.50(-41.00,6.50)$ & 0.70 \\
\hline $\mathrm{T}_{1}-\mathrm{T}_{0}$ oxytocinase $(\mathrm{ng} / \mathrm{mL})$ & 17 & $0.19(0.00,0.46)$ & 9 & $0.05(-0.03,0.14)$ & 0.22 \\
\hline
\end{tabular}

Abbreviations: IQR, interquartile range; SD, standard deviation.

\section{$\mathbf{T}_{\mathbf{0}}$}

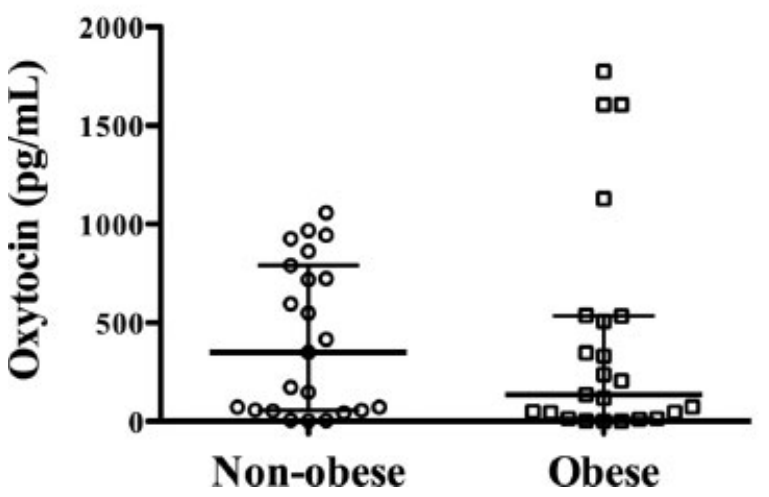

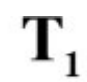

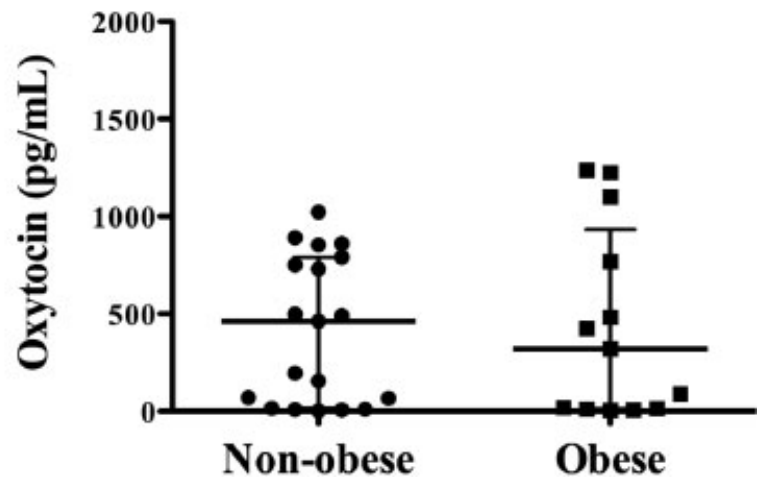

Fig. 2 Scatter plot of plasma oxytocin level $(\mathrm{pg} / \mathrm{mL}$ ) in nonobese (in circles) and obese parturients (in squares) during labor induction and augmentation at time $\mathrm{T}_{0}$ (open shapes) and $\mathrm{T}_{1}$ (closed shapes). There were no significant differences in plasma oxytocin level either at $\mathrm{T}_{0}$ $(p=0.39)$ or at $\mathrm{T}_{1}(p=0.95)$. Data represented as median and interquartile range.

In paired samples from $12 / 18(67 \%)$ in the nonobese group and $7 / 12(58 \%)$ in the obese group, plasma OXT level decreased from baseline after OXT augmentation (-Fig. 4). Neither the $\mathrm{T}_{1}-\mathrm{T}_{0}$ difference for OXT $(-6.50[-96.00,4.00]$ vs. $-1.50[-41.00,6.50] \mathrm{pg} / \mathrm{mL} ; p=0.70)$ nor oxytocinase $(0.19[0.00,0.46]$ vs. $0.05[-0.03,0.14] \mathrm{ng} / \mathrm{mL} ; p=0.22)$ were statistically significant between the nonobese and obese groups, respectively (-Table 2 ). There was no 


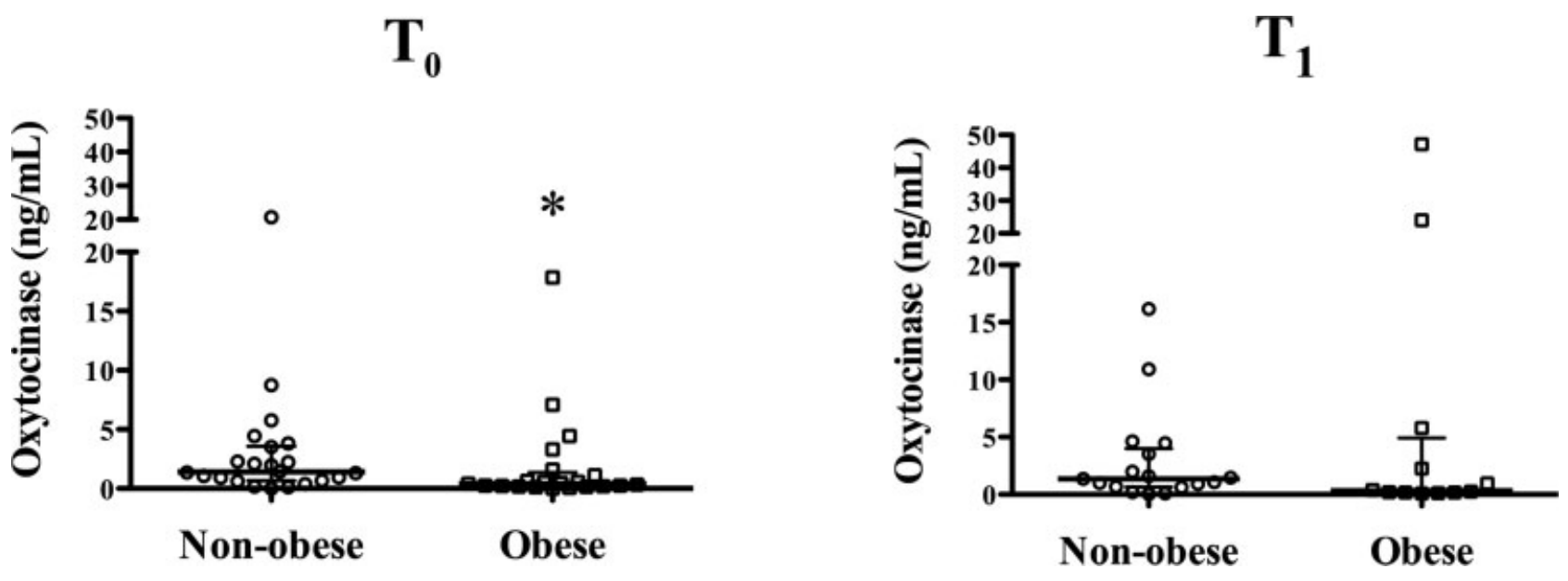

Fig. 3 Scatter plot of plasma oxytocinase level $(\mathrm{ng} / \mathrm{mL})$ in nonobese (in circles) and obese parturients (in squares) during labor induction and augmentation at time $T_{0}$ (open shapes) and $T_{1}$ (closed shapes). Oxytocinase level was significantly lower at $T_{0}\left({ }^{*} p=0.03\right)$ but not at $T_{1}$ $(p=0.44)$. Data represented as median and interquartile range.

significant group versus time interaction in change from $\mathrm{T}_{0}$ to $\mathrm{T}_{1}$ for both OXT $(p=0.51)$ and oxytocinase $(p=0.09)$; therefore, the analysis was re-run without the interaction term. There was neither a significant group ( $p=0.91$ and 0.76 ) nor a time effect ( $p=0.56$ and 0.22 ) for either OXT or oxytocinase, respectively ( - Table 3 ). As cumulative OXT had significant correlations with oxytocinase both at $\mathrm{T}_{0}$ and $\mathrm{T}_{1}$, we analyzed only patients with cumulative OXT data with (-Table 4) and without (-Table 5) cumulative OXT dose as a covariate, but it did not change the overall conclusions. Finally, there was no significant difference in the OXT level at $T_{1}$ between the two groups even after adjusting for the difference in oxytocinase at baseline $\left(\mathrm{T}_{0}\right) \quad(p=0.34)$ (-Table 6).

\section{Discussion}

In this preliminary study, we show that plasma OXT levels were comparable between nonobese and obese women undergoing induction of labor at term gestation, either at baseline or after OXT augmentation. Furthermore, the magnitude of change in plasma OXT level from baseline was no different in either the nonobese or obese women. Interestingly, and contrary to prevailing notion, plasma OXT was lower after OXT augmentation compared with baseline values in a majority of patients with paired samples. Collec- tively, our data suggest that differences in labor outcomes between obese and nonobese parturients are unlikely due to differences in OXT disposition and lay the foundation for a comprehensive pharmacokinetic study.

A prominent feature of our results was the high interindividual variability of plasma OXT in parturients even at baseline. This variability is consistent with a recent study showing a wide range of plasma OXT in pregnant subjects, ${ }^{16}$ though at odds with some studies where the plasma OXT did not vary significantly among parturients during different phases of labor. ${ }^{15,17,18}$ These contradictory observations may partly be accounted for by differences in methodology and sensitivity of reagents in detecting OXT. For example, the choice of assay (radioimmunoassay vs. enzyme immunoassay) and the presence or absence of sample extraction to minimize matrix interference could partly explain these differences. ${ }^{19}$ Nevertheless, our data suggest that this significant interindividual variability should be considered when planning future studies. Another intriguing finding was that plasma OXT decreased after OXT augmentation in $\sim 60 \%$ of parturients. These results defy principles of pharmacotherapy where plasma levels are expected to rise after IV administration. OXT, therefore, presumably behaves more like a hormone in this setting and possibly exerts feedback inhibition to suppress endogenous OXT release. However, currently available ELISA kits are unable to differentiate

Table 3 Mixed-model repeated-measures ANOVA with and without group versus time interaction for oxytocin and oxytocinase

\begin{tabular}{|l|l|l|l|l|}
\hline Analysis & Outcome & $\begin{array}{l}p \text {-Value for } \\
\text { group effect }\end{array}$ & $\begin{array}{l}p \text {-Value for } \\
\text { time effect }\end{array}$ & $\begin{array}{l}p \text {-Value for group } \\
\text { vs. time interaction }\end{array}$ \\
\hline $\begin{array}{l}\text { Repeated measures } \\
\text { with interaction term }\end{array}$ & Oxytocin & 0.88 & 0.49 & 0.51 \\
\hline Repeated measures & Oxytocin & 0.92 & 0.56 & - \\
\hline $\begin{array}{l}\text { Repeated measures } \\
\text { with interaction term }\end{array}$ & Oxytocinase & 0.55 & 0.11 & 0.09 \\
\hline Repeated measures & Oxytocinase & 0.76 & 0.22 & - \\
\hline
\end{tabular}

Abbreviation: ANOVA, analysis of variance. 
e182 Oxytocin and Oxytocinase in the Obese and Nonobese Parturients De Tina et al.

Table 4 Mixed-model repeated-measures ANOVA with and without group versus time interaction for oxytocin and oxytocinase restricted to samples with cumulative oxytocin data as a significant covariate

\begin{tabular}{|l|l|l|l|l|l|l|}
\hline Analysis & $\begin{array}{l}\text { Observations } \\
(N)\end{array}$ & Outcome & $\begin{array}{l}p \text {-Value for } \\
\text { group effect }\end{array}$ & $\begin{array}{l}\text { p-Value for } \\
\text { time effect }\end{array}$ & $\begin{array}{l}p \text {-Value for group } \\
\text { vs. time interaction }\end{array}$ & $\begin{array}{l}p \text {-Value for } \\
\text { covariate }\end{array}$ \\
\hline $\begin{array}{l}\text { Repeated measures } \\
\text { with interaction term }\end{array}$ & 62 & Oxytocin & 0.74 & 0.43 & 0.46 & 0.65 \\
\hline Repeated measures & 62 & Oxytocin & 0.74 & 0.51 & - & 0.64 \\
\hline $\begin{array}{l}\text { Repeated measures } \\
\text { with interaction term }\end{array}$ & 56 & Oxytocinase & 0.47 & 0.27 & 0.22 & $<0.0001$ \\
\hline Repeated measures & 56 & Oxytocinase & 0.44 & 0.42 & - & $<0.0001$ \\
\hline
\end{tabular}

Abbreviation: ANOVA, analysis of variance.

Table 5 Mixed-model repeated-measures ANOVA with and without group versus time interaction for oxytocin and oxytocinase restricted to samples with cumulative oxytocin data but not included as a covariate

\begin{tabular}{|l|l|l|l|l|l|}
\hline Analysis & $\begin{array}{l}\text { Observations } \\
(N)\end{array}$ & Outcome & $\begin{array}{l}p \text {-Value for } \\
\text { group effect }\end{array}$ & $\begin{array}{l}p \text {-Value for } \\
\text { time effect }\end{array}$ & $\begin{array}{l}p \text {-Value for group } \\
\text { vs. time interaction }\end{array}$ \\
\hline $\begin{array}{l}\text { Repeated measures } \\
\text { with interaction term }\end{array}$ & 62 & Oxytocin & 0.76 & 0.43 & 0.45 \\
\hline Repeated measures & 62 & Oxytocin & 0.77 & 0.51 & - \\
\hline $\begin{array}{l}\text { Repeated measures } \\
\text { with interaction term }\end{array}$ & 56 & Oxytocinase & 0.47 & 0.25 & 0.20 \\
\hline Repeated measures & 56 & Oxytocinase & 0.44 & 0.42 & - \\
\hline
\end{tabular}

Abbreviation: ANOVA, analysis of variance.

Table 6 ANCOVA to adjust for baseline differences in oxytocin and oxytocinase

\begin{tabular}{|l|l|l|l|}
\hline Analysis & Outcome & $\begin{array}{l}p \text {-Value for } \\
\text { group effect }\end{array}$ & $\begin{array}{l}p \text {-Value for } \\
\text { group effect } \\
\text { based on ranks }\end{array}$ \\
\hline ANCOVA & Oxytocin & 0.45 & 0.34 \\
\hline ANCOVA & Oxytocinase & 0.23 & 0.72 \\
\hline
\end{tabular}

Abbreviation: ANCOVA, analysis of covariance.

between endogenous and exogenously administered OXT. An important caveat in our study is the higher proportion of cervical ripening in the obese group. This could have changed OXT requirements during induction and augmentation. Conversely, cervical ripening could have affected our primary outcome by elevating baseline OXT in obese subjects either because of physical manipulation of the cervix or by inducing mild uterine contractions. This, along with the small number of paired samples, could possibly explain the significant variability in plasma OXT in the obese group despite similar duration of OXT administration. Our study, therefore, encourages a nuanced understanding of the role of OXT in labor management especially considering that it plays a vital role in areas unrelated to labor such as sexual function, learning, and memory. ${ }^{20,21}$

Despite the extensive and ubiquitous use of OXT for management of labor and delivery, not much is known of its metabolism. Numerous studies have attempted to answer this question by measuring the "activity" of oxytocinase
(LNPEP), an enzyme secreted by the placenta that degrades circulating OXT. ${ }^{22-26}$ Quantitation of oxytocinase "activity" is done fluorometrically by measuring the amount of $\beta$ naphthylamine released from an arylamide substrate after incubation with plasma. ${ }^{27}$ Here, we quantified for the first time, plasma oxytocinase level, rather than activity, and report that it is lower in obese women at baseline compared with nonobese women. As oxytocinase is secreted primarily by syncytiotrophoblasts, ${ }^{24}$ we speculate that this decrease is likely related to placental dysfunction observed in obesity. ${ }^{28}$ Another interesting finding was that the cumulative OXT dose significantly influenced the oxytocinase level at T1. Though the biological significance of these findings is unclear, we hope that our data will encourage future research in this field.

Our study is limited in some ways. First, the lack of serial plasma OXT data to thoroughly characterize its pharmacokinetics. This was ethically challenging given the need for multiple blood draws during what was already a stressful period for an expectant mother. Despite our decision to collect samples at only two time points, $T_{0}$ and $T_{1}$, we were still unable to collect the $\mathrm{T}_{1}$ sample in one-third (36\%) of the enrolled subjects (patient refusal in advanced labor, after hours sample collection, etc.). Furthermore, given the need for immediate sample processing on ice to minimize OXT degradation, it would have been impossible to process multiple samples sequentially on a busy labor and delivery floor. These practical and logistic challenges will serve to inform patient recruitment for future studies. Our study, therefore, can be considered as a preliminary exploration of 


\section{Non-obese}

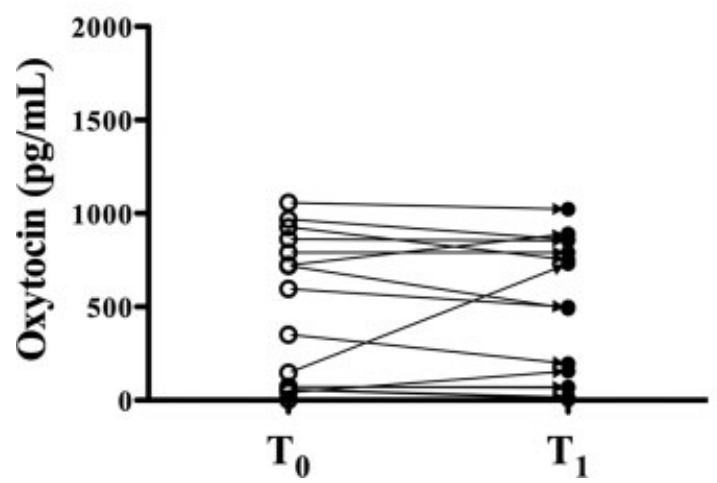

Obese

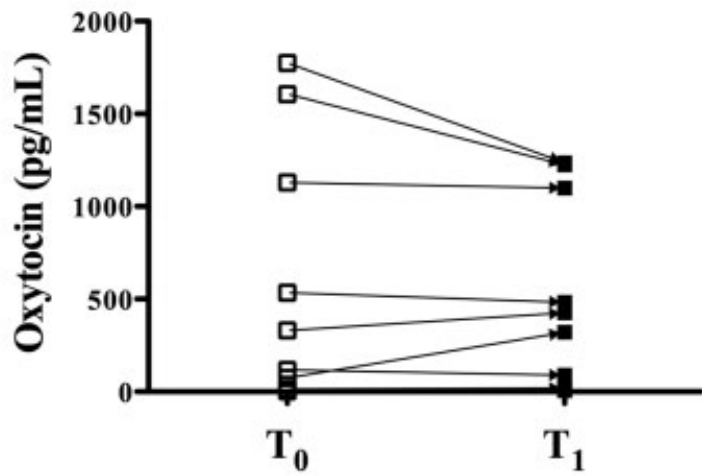

Fig. 4 Before-after plots showing the direction and magnitude of change in plasma oxytocin in nonobese (open to closed circles) and obese (open to closed squares) parturients. In more than $60 \%$ of patients, there was a decrease in plasma oxytocin level after oxytocin augmentation suggesting that oxytocin behaves more like a hormone and less like a pharmaceutical agent in this setting.

OXT disposition in normal weight and obese parturients. Second, the possibility that OXT is metabolized by pathways other than LNPEP ("oxytocinase"). Nevertheless, we targeted LNPEP as it appears to be the predominant mechanism for OXT degradation in pregnant plasma. ${ }^{29,30}$ Third, because of the limited number of paired samples, we were underpowered to investigate the magnitude of change in plasma OXT and oxytocinase both in nonobese and obese subjects. Fourth, we chose prepregnancy BMI for patient recruitment as this was more reliably documented than the BMI on admission. It is reassuring though, that the average gestational weight gain was comparable between the two groups. Finally, because of our interest in quantifying both OXT and oxytocinase from the same sample, we did not use aprotinin, an agent administered to inhibit oxytocinase and prevent OXT degradation. Though this may have introduced some variability, we expect this to be consistent across both groups.

In conclusion, our preliminary study shows that plasma OXT is no different in nonobese and obese parturients, and that OXT augmentation is not accompanied by an increase in plasma OXT in a majority of patients regardless of BMI. Plasma oxytocinase was lower in obese parturients at induction, but it did not seem to influence plasma OXT during augmentation of labor. Therefore, our results lend support to the notion that differences in labor outcomes between nonobese and obese women are probably driven by mechanisms other than simple differences in OXT disposition. However, given the potential clinical implications, we encourage a sample-intensive study to thoroughly characterize OXT pharmacokinetics in nonobese and obese women.

\section{Authors' Contribution}

A.D.T.: This author helped design the study, conducted the study, reviewed analysis, wrote, and approved the final article.

J.J.: This author helped conduct the study, reviewed analysis, wrote, and approved the final article.
T.F.M.: This author helped design the study, reviewed analysis, and approved the final article.

J.D.B.: This author performed statistical analysis and approved the final article.

A.P.: This author conceived the study, designed the study, conducted the study, reviewed analysis, wrote, and approved the final article.

Competing Interest

The authors declare no competing interest.

Conflict of Interest

None.

Acknowledgments

This study was funded by the Society for Obstetric Anesthesia and Perinatology (SOAP) Young Investigator Award 2016. Recipient of the Frederick P. Zuspan Award (J.J.) for collaborative research and scholarship between obstetricians and anesthesiologists, 44th Annual Meeting of the Society for Obstetric Anesthesia and Perinatology in Bellevue, WA, May 10-14, 2017.

\section{References}

1 Mission JF, Marshall NE, Caughey AB. Pregnancy risks associated with obesity. Obstet Gynecol Clin North Am 2015;42(02):335-353

2 Galtier-Dereure F, Boegner C, Bringer J. Obesity and pregnancy: complications and cost. Am J Clin Nutr 2000;71(5, Suppl):1242S-1248S

3 Fyfe EM, Anderson NH, North RA, et al; Screening for Pregnancy Endpoints (SCOPE) Consortium. Risk of first-stage and secondstage cesarean delivery by maternal body mass index among nulliparous women in labor at term. Obstet Gynecol 2011;117 (06):1315-1322

4 Barau G, Robillard PY, Hulsey TC, et al. Linear association between maternal pre-pregnancy body mass index and risk of caesarean section in term deliveries. BJOG 2006;113(10):1173-1177

5 Sherrard A, Platt RW, Vallerand D, Usher RH, Zhang X, Kramer MS. Maternal anthropometric risk factors for caesarean delivery before or after onset of labour. BJOG 2007;114(09):1088-1096 
6 Leddy MA, Power ML, Schulkin J. The impact of maternal obesity on maternal and fetal health. Rev Obstet Gynecol 2008;1(04): 170-178

7 Carlson NS, Hernandez TL, Hurt KJ. Parturition dysfunction in obesity: time to target the pathobiology. Reprod Biol Endocrinol 2015;13:135

8 Norman SM, Tuuli MG, Odibo AO, Caughey AB, Roehl KA, Cahill AG. The effects of obesity on the first stage of labor. Obstet Gynecol 2012;120(01):130-135

9 Kominiarek MA, Zhang J, Vanveldhuisen P, Troendle J, Beaver J, Hibbard JU. Contemporary labor patterns: the impact of maternal body mass index. Am J Obstet Gynecol 2011;205(03):244.e1-244. e8

10 Carlson NS, Corwin EJ, Lowe NK. Oxytocin augmentation in spontaneously laboring, nulliparous women: multilevel assessment of maternal BMI and oxytocin dose. Biol Res Nurs 2017;19 (04):382-392

11 Cheymol G. Clinical pharmacokinetics of drugs in obesity. An update. Clin Pharmacokinet 1993;25(02):103-114

12 Hanley MJ, Abernethy DR, Greenblatt DJ. Effect of obesity on the pharmacokinetics of drugs in humans. Clin Pharmacokinet 2010; 49(02):71-87

13 Gajdosechova L, Krskova K, Segarra AB, et al. Hypooxytocinaemia in obese Zucker rats relates to oxytocin degradation in liver and adipose tissue. J Endocrinol 2014;220(03):333-343

14 von Elm E, Altman DG, Egger M, Pocock SJ, Gøtzsche PC, Vandenbroucke JP; STROBE Initiative. STrengthening the Reporting of OBservational studies in Epidemiology (STROBE) statement: guidelines for reporting observational studies. BMJ 2007;335 (7624):806-808

15 Rahm VA, Hallgren A, Högberg H, Hurtig I, Odlind V. Plasma oxytocin levels in women during labor with or without epidural analgesia: a prospective study. Acta Obstet Gynecol Scand 2002; 81(11):1033-1039

16 Prevost M, Zelkowitz P, Tulandi T, et al. Oxytocin in pregnancy and the postpartum: relations to labor and its management. Front Public Health 2014;2:1

17 Leake RD, Weitzman RE, Fisher DA. Pharmacokinetics of oxytocin in the human subject. Obstet Gynecol 1980;56(06):701-704

18 Leake RD, Weitzman RE, Glatz TH, Fisher DA. Plasma oxytocin concentrations in men, nonpregnant women, and pregnant women before and during spontaneous labor. J Clin Endocrinol Metab 1981;53(04):730-733

19 Szeto A, McCabe PM, Nation DA, et al. Evaluation of enzyme immunoassay and radioimmunoassay methods for the measurement of plasma oxytocin. Psychosom Med 2011;73(05):393-400

20 Caruso S, Mauro D, Scalia G, Palermo CI, Rapisarda AMC, Cianci A. Oxytocin plasma levels in orgasmic and anorgasmic women. Gynecol Endocrinol 2018;34(01):69-72

21 Simpson EA, Paukner A, Sclafani V, Kaburu SS, Suomi SJ, Ferrari PF Acute oxytocin improves memory and gaze following in male but not female nursery-reared infant macaques. Psychopharmacology (Berl) 2017;234(03):497-506

22 Mathur VS, Walker JM. Oxytocinase in plasma and placenta in normal and prolonged labour. BMJ 1968;3(5610):96-97

23 Yamahara N, Nomura S, Suzuki T, et al. Placental leucine aminopeptidase/oxytocinase in maternal serum and placenta during normal pregnancy. Life Sci 2000;66(15):1401-1410

24 Ito N, Nomura S, Iwase A, et al. Ultrastructural localization of aminopeptidase A/angiotensinase and placental leucine aminopeptidase/oxytocinase in chorionic villi of human placenta. Early Hum Dev 2003;71(01):29-37

25 Naruki M, Mizutani S, Goto K, et al. Oxytocin is hydrolyzed by an enzyme in human placenta that is identical to the oxytocinase of pregnancy serum. Peptides 1996;17(02):257-261

26 Oya M, Yoshino M, Mizutani S, Wakabayashi T. The origin of human pregnancy serum oxytocinase. Gynecol Invest 1974;5(56):276-283

27 Ferrier BM, Hendrie JM, Branda LA. Plasma oxytocinase: the synthesis and biological properties of the first product of the degradation of oxytocin by this enzyme. Can J Biochem 1974;52 (01):60-66

28 Howell KR, Powell TL. Effects of maternal obesity on placental function and fetal development. Reproduction 2017;153(03): R97-R108

29 Tsujimoto M, Mizutani S, Adachi H, Kimura M, Nakazato H, Tomoda Y. Identification of human placental leucine aminopeptidase as oxytocinase. Arch Biochem Biophys 1992;292(02):388-392

30 Mizutani S, Sumi S, Oka K, et al. In vitro degradation of oxytocin by pregnancy serum, placental subcellular fractions and purified placental aminopeptidases. Exp Clin Endocrinol 1985;86(03): 310-316 